Focuses on the trajectory of comics towards its artistic and cultural legitimating. Discusses the difficulties for the acceptance of the comics in well established cultural institutions and detaches the work of artists who used the comics language in their works. Brings to context the search for artistic autonomy in underground and mainstream comics. Presents the graphic novels as the new format for the worldwide dissemination of the comics language, making it possible to reach other levels of public and new environments for commerce. Identifies innovative trends in the comics publication field, with emphasis in the use of comics in journalism and in biographical narratives, identifying the main authors in the field.

Keywords: Comix, Auhorship, Art. 


\title{
As histórias em quadrinhos no limiar de novos tempos: em busca de sua legitimação como produto artístico e intelectualmente valorizado
}

\author{
Waldomiro \\ Vergueiro
}

Enfoca a trajetória das histórias em quadrinhos para sua legitimação artística e cultural. Discute as dificuldades para aceitação dos quadrinhos em equipamentos culturais já estabelecidos e destaca o trabalho de artistas que utilizaram recursos da linguagem quadrinística em suas obras. Contextualiza a busca pela autonomia artística em obras produzidas no circuito underground e do quadrinho mainstream. Apresenta as graphic novels como novo formato para disseminação da linguagem dos quadrinhos em nível mundial, possibilitando atingir outras camadas de públicos e novos espaços de comercialização. Identifica tendências inovadoras na publicação de histórias em quadrinhos, com destaque para o jornalismo em quadrinhos e a utilização de quadrinhos para narrativas biográficas, identificando os principais autores e obras na área.

Palavras-chave: Histórias em Quadrinhos; Autoria; Arte. 
As histórias em quadrinhos padeceram durante décadas a indiferença das camadas intelectuais da sociedade, apesar de representarem a continuidade de uma longa tradição de manifestações iconográficas, cuja gênese pode ser encontrada nas pinturas das cavernas do homem pré-histórico e que se desenvolveram durante séculos em diversas formas de manifestações artísticas, como as colunas de Trajano, a Tapeçaria de Bayeux, o Livro dos Mortos, etc. Embora constituindo uma linguagem própria - híbrida da linguagem escrita e da imagem desenhada -, os quadrinhos tiveram sua aceitação pelas elites pensantes dificultada por diversos fatores, mas principalmente por sua característica de linguagem direcionada para as massas. No entanto, os últimos anos parecem ter trazido novos e promissores ventos para as histórias em quadrinhos no que diz respeito à sua inserção no mundo das manifestações artísticas socialmente reconhecidas. Este artigo busca discutir essa trajetória e traçar algumas diretrizes que garantam a permanência dessa forma de manifestação do pensamento humano no campo das Artes.

\section{A luta pela legitimação}

Recentemente, uma conceituada pesquisadora brasileira da área de histórias em quadrinhos, pleiteou a um importante museu de Arte da cidade de São Paulo a instalação de uma grande exposição sobre o tema. Embora não se recusando a abrigar a exposição, os responsáveis pelo equipamento cultural condicionaram sua concordância à justificativa, por parte da professora, de que as histórias em quadrinhos poderiam ser entendidas como Arte. Logicamente, considerando a evolução da linguagem gráfica seqüencial e seu atual estágio de aceitação no mundo artístico contemporâneo, a professora se recusou a elaborar tal justificativa ao museu paulistano, entendendo que a esta altura tal esclarecimento deveria ser dispensável para uma instituição com tão larga trajetória na preservação e divulgação de bens culturais; além disso, pesou também na decisão 
As histórias em quadrinhos no limiar de novos tempos: em busca de sua legitimação como produto artístico e intelectualmente valorizado

o fato desta mesma instituição museológica ter abrigado, na segunda metade do século passado, uma das primeiras exposições de quadrinhos do mundo, demonstrando na ocasião uma postura de vanguarda em relação à postura então dominante no meio intelectual brasileiro e mundial.

De fato, com relação a esse fato, além de salienta-lo e solidarizar-se com a professora pela resposta infeliz por ela obtida, pode-se cogitar que os atuais responsáveis por essa importante instituição artística e cultural da cidade de São Paulo, além de desconhecerem a própria história do órgão que dirigem, fazem ainda parte de uma minoria de intelectuais que persiste vendo a arte como uma "essência metafísica reconhecida pelos seus méritos técnicos, mas, principalmente, pelo seu status filosófico" (MARTINS, 2006, p. 67), da mesma forma em que ignoram ou fingem ignorar os avanços ocorridos na área artística, especialmente no que se refere às histórias em quadrinhos, a partir da década de 1960, quando "uma grande variedade de movimentos - arte pop, arte conceitual, performance, instalações, arte ambiental, etc. - intensificaram abertamente a resistência

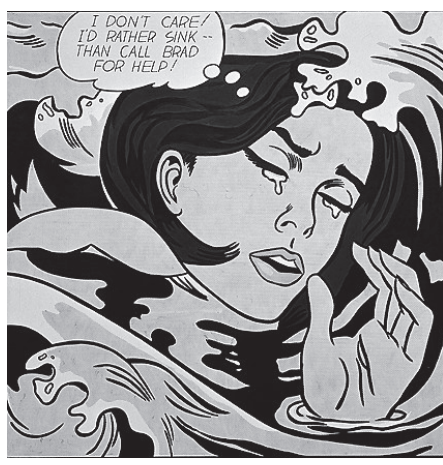

Figura 1 - Roy Lichtenstein, Estados Unidos, 1963. Drowning Girl. Pertencente ao acervo do Museu de Arte Moderna, de New York

às polaridades do sistema das belas artes buscando manter e até mesmo aprofundar a relação entre arte e vida" (MARTINS, 2006, p. 68).

Esses movimentos estiveram mesmo no centro da inserção das histórias em quadrinhos no mundo das artes, pois, na realidade, elas adentraram o ambiente museológico por meio da arte pop, especialmente na obra de artistas como Andy Warhol (19281987) e Roy Liechtenstein (1923-1997), que apreenderam elementos da linguagem gráfica seqüencial e os re-significaram em seus trabalhos artísticos, produzindo intenso impacto visual (Fig. 1).

No entanto, ainda que esses autores tenham representado, no ambiente norte-americano, o começo de um movimento de reconhecimento dos quadrinhos como manifestação artística, eles não se constituíram, absolutamente, em precursores desse 
tipo de valorização da linguagem gráfica seqüencial. Na realidade, o mérito nessa área cabe a diversos intelectuais europeus, mais ágeis em reconhecer o forte impacto social dos produtos quadrinísticos e sobre ele realizando estudos e exposições. Nesse sentido, também não se pode desmerecer a ação visionária de alguns admiradores do gênero no Brasil, que, já em 1951, ainda que sem obter o mesmo impacto no contexto intelectual brasileiro, realizaram a primeira exposição de histórias em quadrinhos em ambiente formalmente constituído como artefato cultural (MOYA, 2001).

Por outro lado, é preciso reconhecer que a classificação de extratos ou páginas de histórias em quadrinhos como objetos museológicos é muito pouco em termos de descrição ou categorização das possibilidades artísticas dos quadrinhos. Bebendo nas águas das mais variadas artes, como a ilustração, o teatro, a literatura, a caricatura e o cinema (BARBIERI, 1998), as histórias em quadrinhos constituem um gênero complexo, em que elementos narrativos de várias manifestações artísticas ou linguagens são explorados.

Esta característica híbrida da linguagem quadrinística, bem como o fascínio que ela tradicionalmente exerceu sobre grandes massas de leitores, principalmente os mais jovens, está talvez no centro de sua rejeição pelas elites intelectuais. Embora compreendidas pelo universo da arte na era da reprodução mecânica, conforme visto por Benjamin (2006 [1969]), elas eram difíceis de classificar e contextualizar. No entanto, talvez em maior medida que a indústria cinematográfica, objeto de atenção do autor alemão, os quadrinhos levavam o aspecto de distração a seu extremo, dificultando sua compreensão por parte dos críticos de Arte. Daí, a incompreensão, o estranhamento.

Isto também dificultou a inserção das histórias em quadrinhos no ambiente acadêmico, em que eles foram virtualmente ignorados durante boa parte do século, independentemente de seu impacto social. Como explicam Lombard e colegas (1999, p. 17),

[...] apesar de seu potencial para a pesquisa, as tiras de quadrinhos, as revistas de histórias em quadrinhos, e os cartuns [...] permaneceram virtualmente não-estudados por décadas. Quando 
a arte dos quadrinhos, na forma de revistas, finalmente achou o seu caminho para os "labs" da universidade Americana nos anos 1940, na maioria das vezes ela era tratada como um pária, um perigo para a juventude, para a moral, para o próprio tecido da sociedade Americana.

A atenção dispensada aos quadrinhos pelos intelectuais ocorreu em paralelo com a emergência de movimentos de produção de quadrinhos que buscavam sua independência das obras disponibilizadas pela indústria massificada - genericamente denominada como quadrinhos mainstream -, colocando-se como auto-suficientes e superiores ao que era então disponibilizado pelas grandes editoras de quadrinhos. Nesse sentido, eles se aliavam, embora muitas vezes não explicitamente, à crítica à indústria cultural feita pelos ideólogos da Escola de Frankfurt, que viam os produtos dessa indústria como essencialmente os mesmos. Como defenderam Max Horkheimer e Theodor W. Adorno (2006 [1944], p. 43-44) em seu famoso texto sobre a indústria cultural,

[...] O padrão unificado de valor consiste no nível conspícuo de produção, a quantidade de investimento evidenciada. As diferenças orçamentárias de valor na indústria cultural não têm nada a ver com diferenças reais, com o significado do produto em si. Os meios técnicos, também, estão sendo engolfados por uma uniformidade insaciável. A televisão busca a síntese do rádio e do filme, atrasada somente enquanto as partes interessadas não podem concordar. Tal síntese, com suas possibilidades ilimitadas, promete intensificar a pobreza da estética material tão radicalmente que a identidade de todos os produtos da indústria cultural, ainda sutilmente disfarçada hoje, irá triunfar abertamente amanhã numa irônica realização do sonho de Wagner da obra de arte total.

Surgido na costa do Pacífico nos Estados Unidos, o movimento dos quadrinhos underground, também conhecidos como comix, bebeu mais especificamente na fonte dos movimentos hippies e da revolta estudantil, representando uma tomada de decisão pelo fortalecimento e autonomia da produção 
quadrinística e sua utilização como meio privilegiado para manifestação artística e social. Fazendo jus ao seu tempo, seus autores, em geral oriundos e atuantes no ambiente universitário, recusavam-se a fazer parte da máquina editorial massificada e massificante, bem como a seguir as normas estabelecidas pelas grandes editoras do país. Extremamente rígidas e reguladas, essas normas eram conseqüência indesejada da ainda recente perseguição aos quadrinhos, ocorrida há apenas uma década e tinham sua expressão concreta no chamado Comics Code, pelo qual cada publicação em quadrinhos era analisada e recebia um selo de aprovação, atestando sua insipiência em relação aos valores socialmente aprovados (NYBERG, 1998).

Os artistas do movimento underground propunham uma criação quadrinística totalmente desvinculada de editoras ou normas editoriais, com obras voltadas para a expressão de sentimentos, para o desafio às tradições e para a liberação de costumes, sem preocupações imediatas com o consumo ou motivações mercantilistas. À frente dessa verdadeira bandeira libertária estiveram nomes posteriormente consagrados no universo dos quadrinhos, verdadeiros ícones em sua proposição como forma de manifestação artística capaz de suplantar as limitações da produção industrializada: Robert Crumb, Gilbert Shelton, Rick Griffin, S. Clay Wilson, Spain Rodriguez, entre outros (SKINN, 2004).

Embora limitado espacial e temporalmente, pois o movimento dos quadrinhos underground teve seu apogeu basicamente entre final da década de 1960 e meados de 1970, a influência tanto de obras como de autores ampliou-se bem além das fronteiras do estado da Califórnia e atingiu os países europeus e latino-americanos, podendo-se afirmar que ajudaram na formulação de um estilo de produção de quadrinhos. Na Europa, eles foram fontes de inspiração para revistas de vanguarda. Nas Américas, por sua vez, assumiram forte viés político-partidário, sendo o estilo preferencial utilizado por artistas latino-americanos para o enfrentamento de governos totalitários que se espalharam pelo continente nas décadas de 1960 e 1970. No Brasil, a influência do quadrinho underground pode ser encontrada na obra do mineiro Henfil e nas colabora- 
ções dos vários participantes do semanário O Pasquim, do Rio de Janeiro, em que as audaciosas alfinetadas nos representantes ou nos (mal)feitos da ditadura militar eram retratados por traços econômicos e esteticamente desafiadores, numa composição que se afastava de cânones mais tradicionais e adentrava pelo universo da caricatura e da sátira (Fig. 2). Esse espectro de atuação das histórias em quadrinhos - mas não exclusivamente delas, uma vez que a revista $O$ Pasquim também abria espaço para a charge, o cartum, a crônica -, também realizava a crítica de costumes, principalmente à classe média acomodada, tão necessária à sociedade da época.

Figura 2 - Grana, de Henfil, publicado em O Pasquim

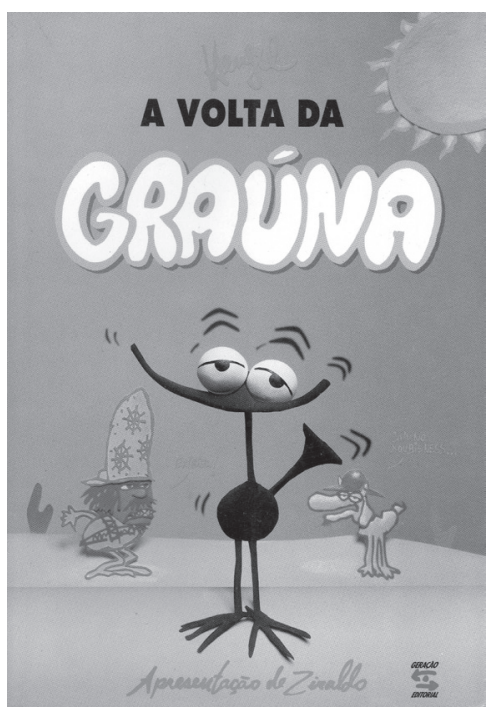

Com o reconhecimento do potencial artístico dos quadrinhos por parte dos intelectuais europeus e com a eclosão do movimento de quadrinhos underground estavam assentadas as bases para uma outra etapa na legitimação cultural das histórias em quadrinhos no mundo inteiro. Pode-se dizer que estava se agilizando o ritmo em que elas deixavam de ser vistas como uma linguagem exclusivamente direcionada para o público de menor idade e passavam a ser encaradas como manifestações voltadas a públicos diversos, com diferentes níveis de qualidade e representação do mundo. 


\section{Marasmo e renovação durante a Era de Prata dos quadrinhos}

De fato, pode-se também afirmar que o processo de reconhecimento das histórias em quadrinhos parece ter avançado por etapas. De um primeiro momento, com as páginas dominicais e tiras diárias, quando foram vistos como forma de assimilação das camadas populares, quase que majoritariamente composta por imigrantes europeus ou asiáticos, à civilização norte-americana, os quadrinhos passaram depois, com as revistas de quadrinhos ou comic-books, a ser direcionados prioritariamente ao público infanto-juvenil, sofrendo as agruras e perseguições de pais e educadores, num movimento de rejeição que se espalhou por praticamente os quatro cantos do mundo.

A verdadeira "ressaca cultural" que seguiu o período mais acirrado de perseguição ao meio - anos imediatamente posteriores à Segunda Guerra Mundial, época da chamada caa $s$ bruxas e apogeu da Guerra Fria entre Estados Unidos e União Soviética, com a proposição do já mencionado Comics Code -, pode ser vista como um momento, ainda que forçado, de preparação para a transposição dos limites da linguagem, àquele tempo ainda aparentemente intransponíveis. Desta forma, à mesmice de uma produção padronizada, massificada e padronizadora seguiu-se um momento de ajuste, em que proposições diferenciadas de produção e composição estética eram expressas em diversas partes do mundo.

Mesmo no âmbito da produção industrializada de quadrinhos era possível vislumbrar indicadores dessa busca por novos parâmetros criativos. Em meio a centenas de títulos e histórias que apenas repetiam um modelo de quadrinhos anódinos, agindo de forma quase subterrânea no ambiente dessa produção industrializada - ou mesmo sob o olhar complacente de seus editores -, alguns autores dos quadrinhos comerciais norte-americanos - aqueles publicados nas revistas de super-heróis, principalmente pelas duas grandes editoras da área, a Marvel e a DC Comics -, incluíam em suas histórias elementos narrativos ou gráficos que as faziam avançar além de produções contemporâneas, transformando-se em marcos para outros autores do 
As histórias em quadrinhos no limiar de novos tempos: em busca de sua legitimação como produto artístico e intelectualmente valorizado

gênero. O trabalho de Jim Steranko à frente do personagem Nick Fury, por exemplo, apresentava diferenças gritantes em relação aos da média dos criadores da época, com designs em que abundavam as fotocolagens e fotomontagens inspiradas em movimentos artísticos como a arte psicodélica e a Op Art. Outro autor que se destacou na produção industrializada de quadrinhos foi Steve Ditko, mundialmente conhecido como um dos criadores do personagem Homem-Aranha, cujos primeiros 38 números foram por ele desenhados. Verdadeiro "mestre da composição, linguagem corporal e ritmo da narrativa" (WOLK, 2007, p. 156), ele se revelou especialmente inspirado no trabalho que realizou para a revista Strange Tales, protagonizada pelo mestre das artes místicas conhecido como Doutor Estranho (Fig. 3). Nessas histórias, contrariamente ao que fazia nas aventuras do Homem-Aranha, em que colocava o herói lutando contra as leis da física,

[...] os personagens em torno do Doutor Estranho eram libertos dessas leis e do mundo em geral, flutuando livremente em outro espaço dimensional cheio com elementos encurvados, de design em garrancho. Não existem quase ângulos retos nas histórias do Doutor Estranho de Ditko além das bordas dos quadrinhos. Vezes e vezes, entretanto, há imagens de portais estranhamente moldados pelos quais planos de existência mais estranhos podem ser vistos, e a implicação é que os retângulos da página impressa atuam como a mesma forma de portal para os leitores (WOLK, 2007, p. 159-160).
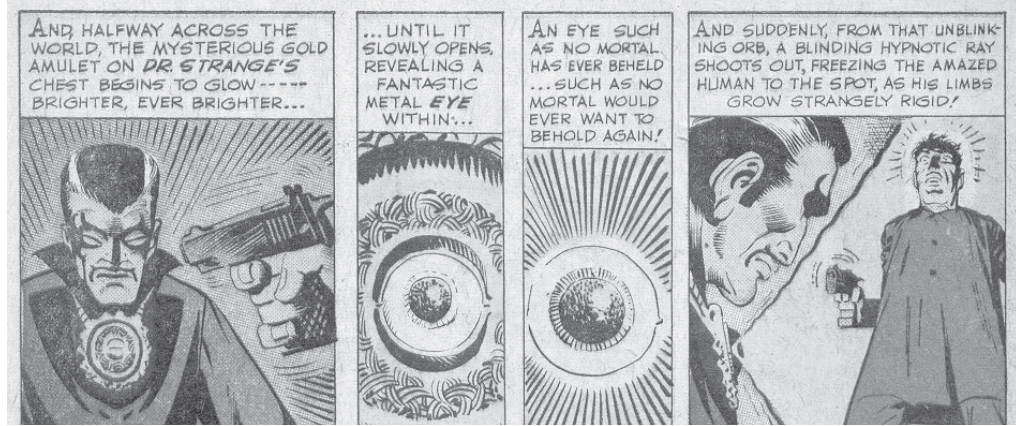

Figura 3 -Doctor Strange, de Steve Ditko, um marco do quadrinho industrializado norte-americano 
O trabalho desses dois autores na Marvel Comics, juntamente com o de artistas como Neal Adams na DC Comics, sinalizavam para alguma coisa inovadora em termos de linguagem das histórias em quadrinhos, que ainda não podia ser suficientemente vislumbrada devido às dificuldades impostas pela mão pesada da censura institucional, desempenhada pelo Comics Code Authority. Essa inovação iria surgir ao final da década de 1970 e viria pelas mãos de um veterano na área, o nova-iorquino Will Eisner (1917-2005). Chamava-se graphic novel.

\section{O surgimento das graphic novels}

Existe uma grande dose de lenda em torno das narrativas que se referem à criação das graphic novels no ambiente quadrinístico norte-americano. Já faz parte do folclore da área a narrativa de Will Eisner sobre a publicação de sua primeira contribuição nessa área, tantas vezes ele se encarregou de contá-la e re-contá-la em entrevistas, palestras e eventos de quadrinhos. Esse episódio é narrado da seguinte forma por Bob Andelman (2005, p. 290):

Eisner telefonou para Oscar Dystel, então presidente da Bantam Books, e jogou o conceito. Dystel não somente conhecia Eisner mas se dizia que era um fã de seu trabalho em The Spirit. Dystel lembrou-se dele, mas era um homem ocupado, como editores normalmente são, e estava impaciente. Ele queria saber o que era que Eisner tinha, exatamente. Eisner olhou para o seu boneco, e um instinto Ihe disse, No diga a Dystel que uma revista em quadrinhos ou ele bater o telefone na sua cara.

Assim Eisner pensou por um momento, e disse: "É uma graphic novel."

"Oh," Dystel disse, "isto parece interessante; eu nunca tinha ouvido falar disso antes."

Por convite de Dystel, Eisner levou o boneco a seu escritório. Dystel olhou o boneco, olhou para Eisner em descrença, e então olhou de volta para o boneco. Então Dystel balançou sua cabeça. "Chame isso do que você quiser," ele disse tristemente, "mas isto é ainda uma revista em quadrinhos! Nós não vendemos revistas em quadrinhos na Bantam. Eu estou surpreso com você, Will. Vá 
As histórias em quadrinhos no limiar de novos tempos: em busca de sua legitimação como produto artístico e intelectualmente valorizado

em busca de um pequeno editor."

Na realidade, Eisner não havia criado nada novo, por mais que afirmasse que a idéia the viera repentinamente. Ele não havia absolutamente inventado a expressão graphic novel, pois não se tratava da primeira vez que ela era utilizada em relação especificamente a um produto quadrinístico. Antes de Eisner, o termo já havia sido utilizado pelo crítico de quadrinhos norte-americano Richard Kyle, em 1964, e também por Henry Steele na revista Fantasy illustrated, em 1966. Da mesma forma, o trabalho que Eisner então oferecia ao editor - Um contrato com Deus -, tampouco poderia ser considerado de fato a primeira graphic novel a ser publicada no ambiente de quadrinhos norte-americano, com diversas obras podendo ser apontadas como suas antecessoras (destacando-se, neste aspecto, Jungle book, the Harvey Kurtzman, e Beyond time and again, de George Metzger, para apenas citar dois exemplos).

Por outro lado, a própria idéia compreendida pela expressão graphic novel pode ser facilmente contextualizada em outros países, com destaque para os álbuns encadernados de histórias em quadrinhos, já naquela época correntemente publicados no ambiente europeu, em geral trazendo histórias completas de personagens consagrados, anteriormente publicadas na forma de capítulos em revistas como Tintin, Spirou ou Pilote. Foi a partir desses álbuns que o crítico Richard Kyle, já mencionado, cunhou inicialmente o termo graphic story, que rapidamente substituiria por graphic novel, visando inspirar os autores norte-americanos a adotarem o mesmo nível de sofisticação das publicações européias (GRAVETT, 2005, p. 8).

No entanto, polêmicas à parte, é preciso reconhecer que Will Eisner, com seu prestígio como criador da área e inteligente atuação mercadológica, foi de capital importância para a popularização do termo e ampliação do mercado para esse tipo de publicação. Após algumas rejeições, ele finalmente conseguiu publicar Um contrato com Deus pela Baronet Books, em 1978 (Fig. 4). Tratava-se de uma coletânea de quatro histórias sobre pessoas que Eisner havia conhecido durante sua infância e adolescência no Bronx; na obra, o autor fugia do formato original dos quadrinhos, evitando contar a trama quadro a quadro 


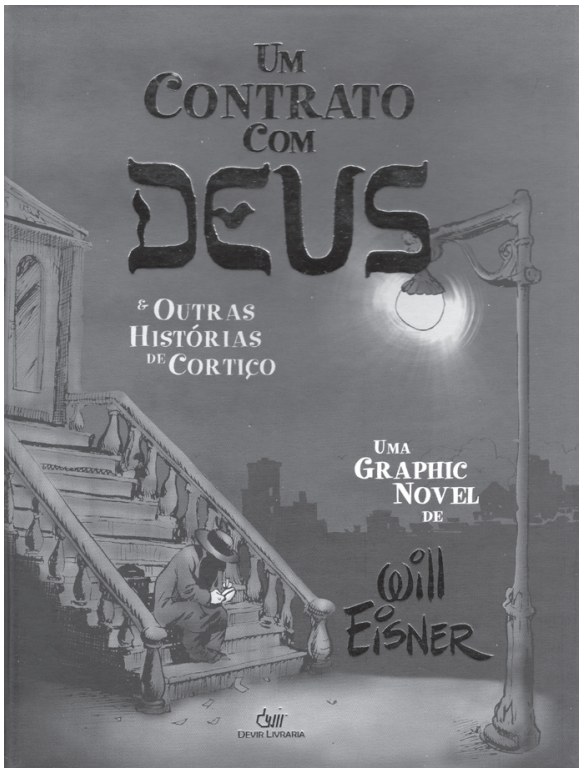

e às vezes utilizando a página inteira para uma única ilustração.

Figura 4 - Um contrato com Deus, de Will Eisner, considerada por muitos como a primeira

A obra não atingiu um sucesso imediato, mas aos poucos sua qualidade foi se impondo e a reação a ela se solidificando de forma calorosa e encorajadora, a partir de sua difusão entre o público adulto. Isso Ihe garantiu sucessivas reimpressões. De uma certa forma, a aceitação do trabalho representava o apoio dos leitores às idéias de Will Eisner e à sua proposta de modificar os estereótipos que existiam em relação às publicações de histórias em quadrinhos.

Por mais que a expressão graphic novel represente um termo com diferentes acepções, é possível dizer que ela veio a influir positivamente no ambiente dos quadrinhos no mundo inteiro, predispondo leitores e críticos não só a uma nova forma de publicação de histórias em quadrinhos, mas, também, a uma nova formulação artística para o gênero. Tratava-se de uma nova maneira de viabilizar e disseminar os quadrinhos, um novo pacote, no dizer de Charles Ha- 
As histórias em quadrinhos no limiar de novos tempos: em busca de sua legitimação como produto artístico e intelectualmente valorizado

tfield (2005), que viria a somar aos já existentes. Segundo esse autor,

A história a arte dos quadrinhos se formou nas histórias de certos pacotes ou formatos. Nos Estados Unidos, o mais dominante desses pacotes foi a página de jornal e a "revista em quadrinhos." O primeiro consiste de uma miscelânea de traços e gêneros, a maioria contida pelas rígidas barreiras da tira diária ou da dominical; ele aparece no interior da mais ampla miscelânea dos jornais, e quadrinhos produzidos para ele são vistos no máximo como tipos secundários. A chamada revista em quadrinhos, por outro lado, é uma revista pequena e auto-contida ou panfleto (mais ou menos de tamanho meio tablóide). Nos primeiros dias da indústria, esta revista incorporava uma miscelânea de gêneros, tanto narrativos como não-narrativos; mais recentemente, no entanto, ele veio a se concentrar em um único personagem ou grupo de personagens e, mais freqüentemente, em uma única história (tipicamente entre dezoito ou vinte e quatro páginas de extensão). Desde o final dos anos 1980, uma terceira forma de empacotamento de quadrinhos ganhou espaço na cultura impressa Americana: a "graphic novel", o que no jargão da indústria significa qualquer narrativa quadrinística em tamanho de livro ou um compêndio de tais narrativas (excetuando volumes de reimpressão de tiras de jornal, que compõem um gênero longevo, ainda que criticamente invisível em si mesmo). Cada um desses três pacotes, a página de quadrinhos, a revista em quadrinhos, e a graphic novel, tem seus próprios horizontes em termos de conteúdo, audiência e aporte cultural.

A nova denominação ajudou a abrir as portas de outros espaços de comercialização e exposição para as produções quadrinísticas, elevando-as a um novo patamar no espectro das criações artísticas no último quarto do século 20 e início do século 21. Mais que isso: como formato de produção, as graphic novels tornaram possível quebrar a barreira entre os quadrinhos industrializados e os alternativos, criando condições para um mercado diferenciado, em que a qualidade artística, o aprofundamento psicológico, a ousadia do design e a complexidade temática passaram a ter seu valor melhor equacionado. Pode-se dizer que, a 
partir delas, as histórias em quadrinhos se firmaram como a 9 Arte ou como Arte Seqencial.

\section{Os caminhos da Arte Seqüencial}

A partir da década de 1980, as histórias em quadrinhos passaram a ser referenciadas como a $9^{a}$ Arte. Nisso, completavam um conjunto formado por artes mais tradicionais (as seis primeiras: música, dança, pintura, escultura, literatura e teatro), acrescidas de duas outras de criação mais recente, o cinema e a fotografia (embora não fique muito claro porque o cinema, posterior à fotografia, mereceu a $7^{a}$ colocação...). Quase que paralelamente, as histórias em quadrinhos passaram a ser também mencionadas como Arte Seqüencial, uma denominação pouco satisfatória, uma vez que, a rigor, poderia se referir não apenas às histórias em quadrinhos, mas também a outras artes com as mesmas características, como o cinema e a animação (razão pela qual, este autor prefere utilizar a expressão arte grfica seqencial para fazer referência às histórias em quadrinhos...). Isto, no entanto, talvez não tenha tanta importância, mas sim a proposição das histórias em quadrinhos como arte, objetivo que a expressão parece atender satisfatoriamente. De qualquer forma, já no início da década de 1980 intensificou-se o uso desse termo por pesquisadores e artistas. Mais uma vez, foram liderados por Will Eisner, que o utilizou em um curso sobre quadrinhos que ministrou na School of Visual Arts da cidade de Nova lorque e posteriormente como título de seu primeiro livro teórico na área (EISNER, 2001 [1985]). Tal como ele, outros artistas trataram de divulgar essa denominação em eventos e publicações da área.

Tratou-se de mais um passo na busca da legitimação cultural da linguagem. Nesse sentido, Thierry Groensteen, analisando a realidade dos quadrinhos a partir da situação européia, também identifica dois momentos na história recente, bem semelhantes ao que se passou no ambiente norte-americano: em primeiro lugar, a reconquista do leitor adulto, ocorrida a partir de 1972, com o lançamento da publicação 
As histórias em quadrinhos no limiar de novos tempos: em busca de sua legitimação como produto artístico e intelectualmente valorizado

LEcho de Savanes, considerada por ele como a primeira revista "somente para adultos"; em segundo lugar, o crescimento da publicação de álbuns na França, ocorrida quase que em paralelo com o desaparecimento das revistas tradicionais de quadrinhos do país, Tintin, Pif, Pilote, Charlie, Metal Hurlant. Nesse sentido, Didier Pasamonik (2008, p. 15) complementa o pensamento de Groensteen, afirmando que

[...] Do início dos anos 90 e em um crescendo nos anos seguintes, não houve um grande editor de literatura que não tenha buscado publicar histórias em quadrinhos: Albin Michel, Gallimard, Grasset, Le Seuil, Flammarion, Hachette, Denoël, Fayard, Le Diable Vauvert, Buchet-Chastel, La Martinière[...]

Ao mesmo tempo, do outro lado do mundo, grupos de artistas que poderiam ser considerados

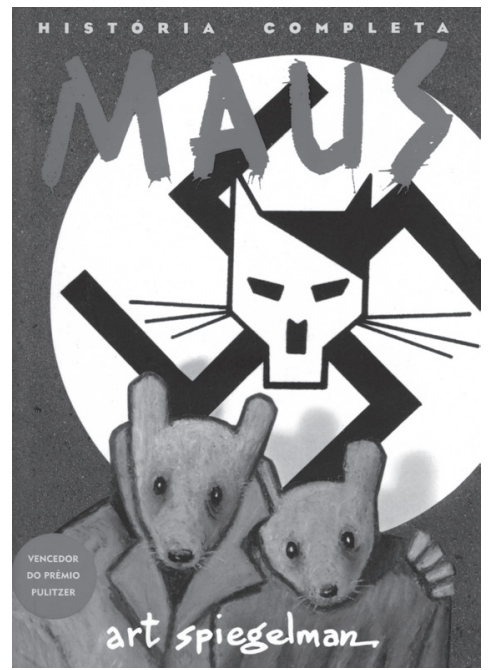

Figura 5 - Maus, de Art Spiegelman, sucesso junto à crítica norte-americana como sucessores do movimento underground norte-americano passaram a ter maior destaque no universo dos quadrinhos norte-americanos. Colaborou fortemente para isso a proeminência obtida por Art Spiegelman e sua obra Maus. Com pretensões nitidamente biográficas, Maus trazia a história dos pais do autor, que haviam sido prisioneiros em um campo de concentração alemão durante a Segunda Grande Guerra. Utilizando uma narrativa em primeira pessoa, na qual ele próprio contracena com seu pai e o faz recordar os momentos terríveis da perseguição aos judeus durante o conflito mundial, com todas as conseqüências psicológicas e pessoais que o período de confinamento havia trazido, Spiegelman utiliza um recurso característico das fábulas e das histórias em quadrinhos infantis: retrata os personagens como animais, individualizando as diversas nações por tipologias zoológicas - os judeus como rato, os alemães como gatos, os ingleses como cães, os poloneses como porcos, etc. (Fig. 5) 
Tendo sido inicialmente publicado em capítulos na revista Raw, fanzine sofisticado de histórias em quadrinhos de vanguarda, editada por Spiegelman e Françoise Mouly de 1980 a 1991, Maus, após sua publicação em formato graphic novel, recebeu em 1992 um prêmio Pulitzer especial. Desta forma, com ele, escancarava-se para o mercado norte-americano e para o mundo em geral o potencial do novo formato de disseminação de quadrinhos, que não mais precisava ficar vinculado a narrativas nos gêneros tradicionais - super-heróis, policiais, aventuras, etc. - mas podia ser explorado para incursões no campo da história, da memória social e do jornalismo. Criavam-se - ou, melhor dizendo, solidificavam-se - assim novas expectativas em relação ao meio. Na realidade, pode-se dizer que com ele se quebrava também um preconceito, o de que histórias em quadrinhos não se prestam à retratação episódios históricos especialmente problemáticos, como o Holocausto dos judeus na $2^{a}$. Guerra Mundial. Como menciona Rocco Versaci (2007, p. 82)

Um meio que parece mesmo menos equipado para comunicar esta particular história seria o da revista em quadrinhos. De fato, em termos de concepções populares, seria difícil encontrar dois assuntos mais discrepantes que o Holocausto e as revistas em quadrinhos, pois a última é comumente encarada como uma diversão imatura enquanto o primeiro, por contraste, se tornou congelado na maioria das mentes como uma metáfora para o mal absoluto, tão amplos são seus horrores. Ambas as percepções são infortunadas, pois nem o Holocausto nem as revistas em quadrinhos são bem servidas por essas generalizações. Apesar da aparente incongruência entre quadrinhos e o Holocausto, entretanto, Art Spiegelman ousadamente une os dois em suas graphic novels Maus I (1986) e Maus II (1991).

O reconhecimento obtido por Spiegelman chamou a atenção do público em geral, que de repente se viu defronte a uma realidade já familiar aos admiradores do gênero, a muitos artistas atuantes na indústria de quadrinhos e àqueles que se haviam aventurado na produção de quadrinhos underground. Face a essa nova realidade, pode-se dizer que o cabedal social das histórias em quadrinhos foi objeto de forte valoriza- 
As histórias em quadrinhos no limiar de novos tempos: em busca de sua legitimação como produto artístico e intelectualmente valorizado

ção, passando elas a terem um novo tipo de recepção. A este movimento veio se somar a entrada no mercado ocidental das produções de quadrinhos japonesas - os mangás -, que propunham uma estética diferenciada em relação aos quadrinhos mainstream, com obras que se colocavam, em princípio, como buscando horizontes mais ambiciosos que a produção tradicional ocidental. E esta invasão nipônica se fez inicialmente por obras que se destacavam em termos de qualidade Gen Ps Descalos, de Keiji Nakazawa, que transitava pelo mesmo espaço memorialístico de Maus (Fig. 6). Nele, em uma narrativa emocionante, o autor relembra sua trágica experiência de vida, quando, ainda menino, esteve presente na cidade de Hiroshima durante o lançamento da primeira bomba atômica pelos Estados Unidos, perdendo parte de sua família durante o conflito e sofrendo danos psicológicos ir-

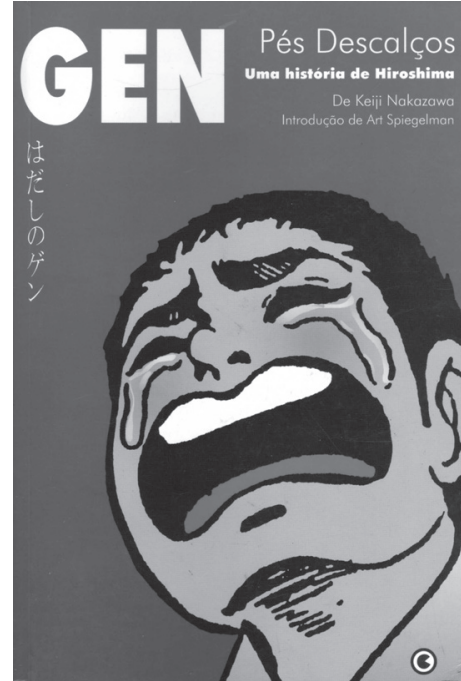

Figura 6 - Gen Ps Descalos, de Keiji Nakazawa, uma comovente história sobre as agruras da guerra e o sofrimento causado pela bomba de reparáveis.

Face à invasão japonesa e à boa acolhida da obra de Spiegelman, os grandes editores comerciais intensificaram a produção não apenas de graphic novels, mas também de mini-séries em sua linha normal de produção. Assim, um movimento que havia começado em 1986 com o objetivo de revitalizar um dos ícones da editora DC, o personagem Batman - com Batman: O Cavaleiro das Trevas, de Frank Miller e Klaus Janson (Fig. 7) -, passou a ter um ritmo muito mais rápido de lançamentos, muitas vezes representando obras especialmente criadas para o novo formato, outras vezes coletando histórias ou arcos de histórias aparecidos nas edições normais, ou seja, em revistas de linha. Nesse espírito ocorreu o aparecimento de obras que depois se revelariam de capital importância na revitalização 
do gênero dos quadrinhos de super-heróis, como Watchmen (1986), de Alan Moore e Dave Gibbons; Demolidor: A queda de Murdoch (1986), de Frank Miller e David Mazzuchelli; Batman: Ano Um (1987), de Frank Miller e David Mazzuchelli; Batman: a piada mortal (1988), de Alan Moore e Brian Bolland; Batman: Asilo Arkham (1989), de Grant Morrison e Dave McKean; Marvels (1991), de Kurt Busiek e Alex Ross; Astro City (1995), de Kurt Busiek e Brent Anderson; e O Reino do Amanh (1996), de Mark Waid e Alex Ross, entre outros (KANNENBERG, 2008).

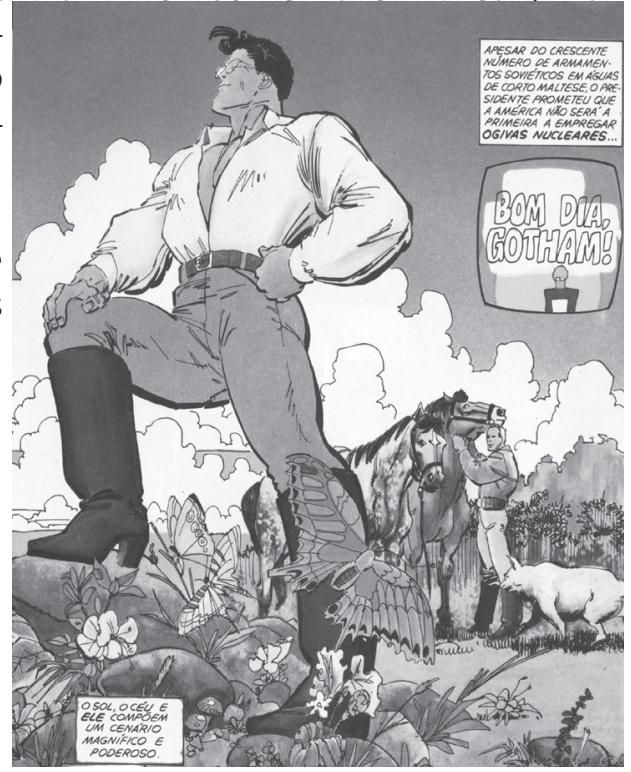

Figura 7 - Batman: O Cavaleiro das Trevas, obra significativa de um novo momento dos quadrinhos de super-heróis

Além das histórias protagonizadas por super-heróis, outras obras surgiram no mercado mainstream buscando a excelência 
As histórias em quadrinhos no limiar de novos tempos: em busca de sua legitimação como produto artístico e intelectualmente valorizado

artística e atingir um público mais adulto, muitas delas sendo extremamente bem sucedidas em ambos objetivos. Entre elas, deve-se destacar a contribuição de Neil Gaiman e Dave McKean em Violent Cases (1987), publicada originalmente na Inglaterra, dois anos antes de Gaiman dar início à obra pela qual ficou mais conhecido, Sandman (1989-1996), que realizou com diversos desenhistas. Outro trabalho semelhante que esse escritor realizou no gênero fantasia foi Os Livros da Magia (1990), também com diversos autores e com a mesma qualidade estética e literária de Sandman, mas sem atingir o mesmo sucesso.

Outro autor que também enveredou pelo universo das graphic novels foi o inglês Alan Moore, com diversas obras de grande sucesso lançadas pela editora que fundou, a American Best Comics, posteriormente transformadas em graphic novels. Dirigidas ao público mais adulto, todas essas obras brincam com elementos fantasiosos e revisitam os diversos gêneros dos quadrinhos, como o de super-heróis (Top Ten, Supremo), fantasia (Prometea), drama (A small killing, Lost girls), humor (D. R. and Quinch), aventura ( $A$ Liga Extraordinria) e ficção científica ( $V$ de Vingana, $A$ balada de Halo Jones, Skizz).

No entanto, mais do que salientar esses e outros incríveis autores e suas obras maravilhosas, talvez seja mais produtivo encara-los, em seu conjunto, como um testemunho vivo do avanço qualitativo da arte seqüencial mesmo no mercado mainstream. Além disso, é importante também destacar que o crescimento da oferta de graphic novels permitiu a utilização da linguagem dos quadrinhos para a exploração de diversos gêneros que haviam sido tratados apenas marginalmente por ela. E isso ocorreu de tal maneira que uma nova classificação temática foi gerada na área, com trabalhos que jogaram por terra todas as idéias pré-concebidas sobre as limitações da linguagem quadrinística para ir além de propostas ficcionais.

Nessa linha, um dos pontos altos da área na última década foi o surgimento do gênero atualmente conhecido como jornalismo em quadrinhos, voltado para a documentação de acontecimentos e fatos reais. O destaque nessa área é o jornalista e artista de quadrinhos Joe Sacco, cujas obras se transformaram em modelos para todos aqueles que intentam enveredar pelas mesmas veredas cria- 


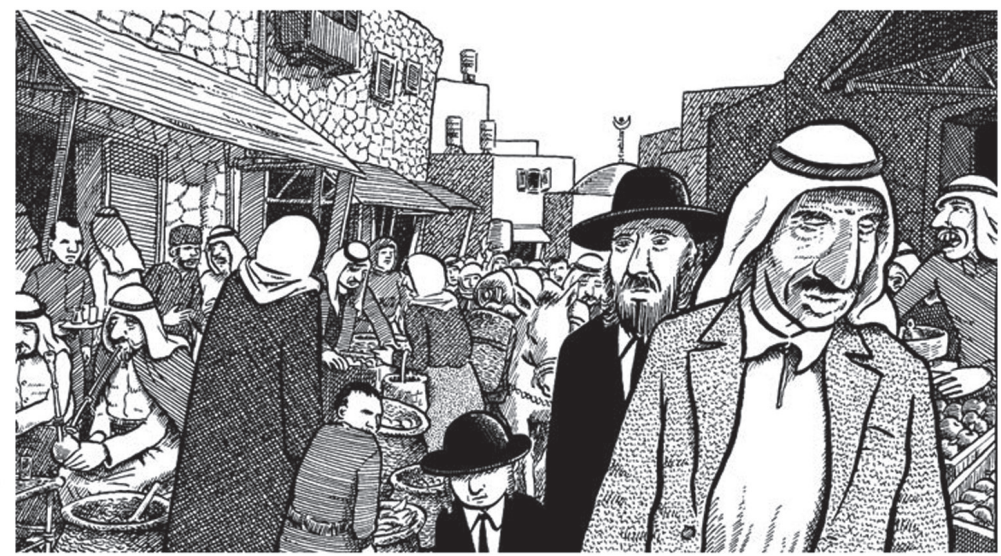

Figura 8 - Palestina, de Joe Sacco, a ponta de lança de um novo gênero quadrinhístico, o jornalismo em quadrinhos

tivas. Palestina: uma nao ocupada (Fig. 8), sua primeira obra nessa linha, publicada originalmente em 1993, é um relato de sua viagem aos territórios ocupados da Palestina, retratando com muita sensibilidade a rotina dos moradores e dando voz a um povo que convive cotidianamente com a privação em um país militarmente ocupado. Seus desenhos, em estilo underground, evidenciam um autor comprometido com aquilo que está retratando, nitidamente tomando o partido daqueles que entrevista, participando de demonstrações, assistindo a funerais e até mesmo dividindo suas provisões e acomodações com membros da comunidade palestina.

Sacco publicou várias obras com o mesmo objetivo de Palestina, assentando as bases em que outros autores também trabalharam ou continuam a trabalhar. Desta forma, alinhadas com o chamado Novo Jornalismo, essas obras quadrinísticas se impuseram por uma narrativa pessoal e relatos de eventos da vida real. A importância desse trabalho não pode ser subestimada. Segundo Rocco Versaci (2007, p. 111), esses

[...] quadrinistas jornalistas aproveitaram ao máximo a linguagem gráfica do meio para reanimar a mais distintiva característica do Novo Jornalismo: o aprofundamento da perspectiva do indivíduo como um organizador da consciência. Além disso, os quadrinistas jornalistas atingem camadas de significado inacessíveis ao jornalismo 
As histórias em quadrinhos no limiar de novos tempos: em busca de sua legitimação como produto artístico e intelectualmente valorizado

em prosa sozinho devido à linguagem gráfica dos quadrinhos que agrega palavras e imagens. E ainda mais, como os Novos Jornalistas, os quadrinistas jornalistas abraçam uma destacada atitude anti-"oficial", anticorporação. Entretanto, diferentemente da absorção do Novo Jornalismo pela indústria e a resultante diluição de sua mensagem radical, os quadrinistas jornalistas retêm, paradoxalmente, um poderoso status marginal que dificultará que esses trabalhos sejam totalmente "co-optados." Quando alguém fala sobre a literatura do jornalismo, trabalhos de quadrinistas jornalistas devem ser incluídos, pois eles proporcionam histórias e levantam importantes questões de representação e verdade de maneiras que não estão disponíveis ao jornalismo estritamente em prosa, "Novo" ou de outro modo.

Além do jornalismo em quadrinhos, outro gênero que adquire força nesse novo momento de legimitação das histórias em quadrinhos é a narrativa pessoal, enfocando relatos de vida e memórias. É um gênero que tem suas raízes no quadrinhos underground, principalmente com o trabalho de Robert Crumb, e que posteriormente, com seus sucessores no âmbito do hoje denominado quadrinho alternativo, atingiu níveis de qualidade antes pouco vislumbrados, mesmo pelos admiradores do gênero. Ele já aparece claramente nas já mencionadas

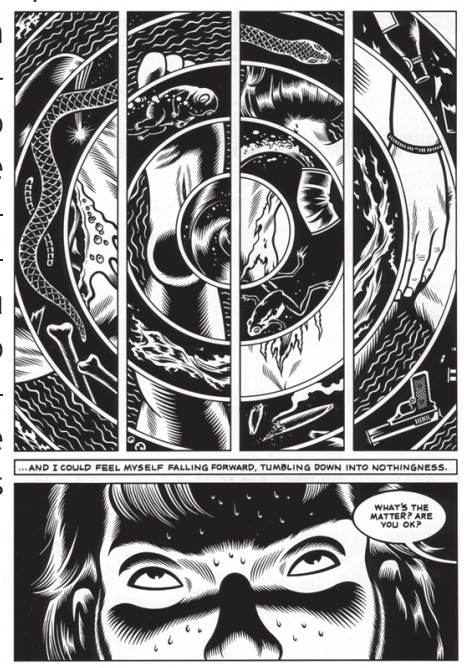

Figura 9 e 10 - Black Hole e Na Priso, obras que dão continuidade ao gênero biografia em quadrinhos, com grande profundidade artística

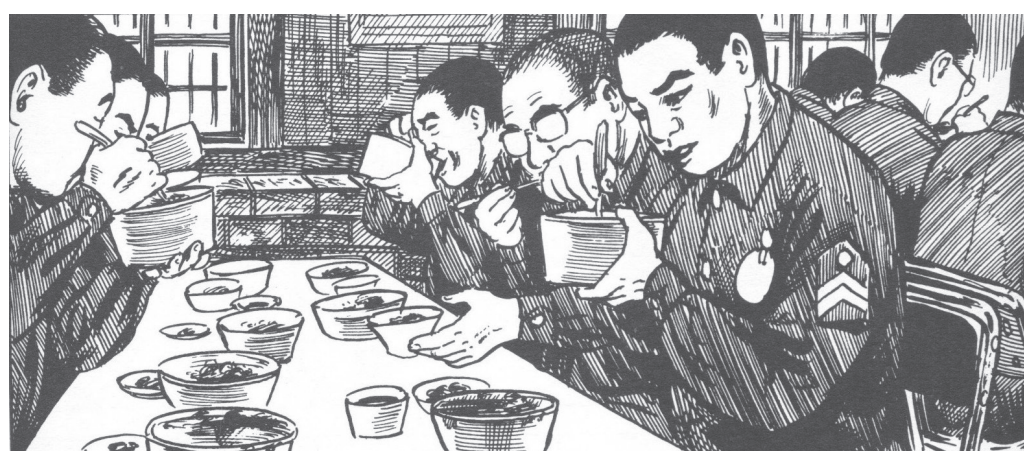


obras de Art Spiegelman e Keiji Nakazawa, mas se aprofunda de forma significativa nos trabalhos de autores como o norte-americano Charles Burns e o japonês Kazuichi Hanawa.

O primeiro retrata em Black Hole (Fig. 9), uma extensa graphic novel elaborada em imagens luxuriantes, ousadas e bastante perturbadoras, que levou dez anos para ser concluída, a época da sua juventude, na década de 1970, e a convivência diária com drogas e sexo, colocando a nu momentos de fragilidade e indecisão frente a um mundo que parecia não the oferecer as respostas que buscava. O segundo expõe em Na Priso (Fig. 10) a época em que seu autor esteve confinado em uma prisão japonesa, devido a uma acusação de porte ilegal de armas, descrevendo o dia-a-dia de seu confinamento.

Outros gêneros mais tradicionais dos quadrinhos também tiveram grande desenvolvimento nos últimos anos. Sem querer esgotar o assunto, é possível destacar Sincity, de Frank Miller, Cidade de Vidro, de Paul Auster e David Mazzucchelli, Estrada para a Perdio, de Max Alan Collins e Richard Piers Rayner, nos quadrinhos policiais; Moonshadow, de J. M. DeMatteis e Jon J. Muth, no gênero fantasia; Birdland e Crnicas de Palomar, de Gilbert Hernandez, Ghost World, de Daniel Clowes, Strangers 
in Paradise, de Terry Moore, Jimmy Corrigan, the smartest kid in the world, de Chris Ware, em histórias do cotidiano; Hellboy, de Mike Mignola, nas histórias de terror; Os Invisveis, de Grant Morrison, Akira, de Kathuhiro Otomo, Hard Boiled, de Frank Miller e Geoff Darrow, Give me Liberty, de Frank Miller e Dave Gibbons, The Originals, de Dave Gibbons, na ficção científica; Pussey!, de Daniel Clowes, Buddy does Seattle, de Peter Bagge, Quimby the Mouse, de Chris Ware, no humor (KANNENBERG, 2008).

Em todos os títulos acima mencionados - e em muitos outros que não foram incluídos por absoluta falta de espaço -, pode-se observar a preocupação com a elaboração de histórias que fujam do comum e tenham a marca do seu autor. Algumas apresentam uma visão acerba e crua da sociedade, em desenhos aparentemente grotescos e mesmo horripilantes. Outras buscam proporcionar deleite estético em níveis similares aos proporcionados pelas outras artes, inspirando-se abertamente em grandes obras da representação pictórica universal. 


\section{Conclusão}

Em sua obra Reading comics: how graphic novels work and what they mean, Douglas Wolk (2007, pag. 10) argumenta, em relação à evolução das histórias em quadrinhos, que "se existe tal coisa como uma idade de ouro dos quadrinhos, ela está acontecendo exatamente agora." Analisando a produção atual e o nível de qualidade de imagens e roteiros encontrados em muitas produções quadrinísticas, não se pode deixar de concordar com esse autor. Estamos, sim, vivendo uma grande época para os quadrinhos.

Por outro lado, não se pode deixar de reconhecer que a produção industrializada continua massiva e massificante: toIhida em limites mais amplos do que os de vinte ou trinta anos atrás, é certo, mas, ainda assim, com evidentes limitações. A oferta de quadrinhos como um todo, considerada a produção industrial, continua disponibilizando, em proporções bastante exageradas - cerca de 80 ou 90 por cento, dependendo do ponto de vista -, daquilo que poderia ser denominado como lixo, ou seja, quadrinhos padronizados e presos a um modelo industrializado de produção, voltados para a reprodução das mesmas histórias a serem consumidas pelas mesmas massas de leitores invisíveis e não-identificados. Apenas uma pequena parcela da produção continua a ser composta por obras que realmente colaboram para o avanço da linguagem dos quadrinhos e sua evolução artística, enquanto todo o restante da produção busca perpetuar o interesse da sociedade em geral por esse meio de comunicação de massa. Mas nisso as histórias em quadrinhos não se diferenciam de todas as outras artes, pois fato semelhante pode ser encontrado no cinema, no teatro, na literatura, etc. Ambas as tipologias de produção - o lixo, por um lado, e a arte, por outro -, cumprem muito bem o seu papel.

A boa notícia é que as obras que fazem avançar a linguagem quadrinística já não se situam mais somente no âmbito do quadrinho alternativo. Cada vez mais, é possível encontrar no contexto de quadrinhos mainstream obras que, embora tratando de temáticas aparentemente padronizadas, re-elabo- 
As histórias em quadrinhos no limiar de novos tempos: em busca de sua legitimação como produto artístico e intelectualmente valorizado

ram a linguagem e influem significativamente em seu aprimoramento. E isso ocorre com freqüência cada vez maior.

Existem motivos para otimismo em relação à legitimação das histórias em quadrinhos na sociedade. Embora algumas portas de instituições culturais ainda permaneçam estupidamente fechadas para acesso e valorização das produções quadrinísticas, outras já se abrem e algumas até mesmo se escancaram para elas. Bibliotecas, que antes sequer cogitavam em armazenar quadrinhos, já as oferecem abertamente. Livrarias criam seções especiais para comercialização de graphic novels, álbuns e mini-séries. Escolas são tomadas por professores e alunos ávidos pela utilização de histórias em quadrinhos em sala de aula. São novos tempos.

Exercícios de futurologia são sempre arriscados. Assim, seria provavelmente arriscado fazer qualquer tipo de prognóstico em relação ao futuro da arte gráfica seqüencial. Existe um caminho a ser percorrido, talvez ainda com algumas dificuldades. Autores e leitores, no entanto, parecem cada vez menos temerosos em relação a ele e o vêem como uma grande promessa. $\mathrm{E}$ talvez realmente o seja.

\section{Notas}

1. Informação oral, prestada informalmente em junho de 2008. Os nomes foram omitidos, por decisão deste autor, visando evitar constrangimentos aos envolvidos.

\section{Referências}

ANDELMAN, Bob. Will Eisner: a spirited life. Milwaukie Press, 2005.

BARBIERI, Daniele. Los lenguajes del cmic . Barcelona: Paidós, 1998.

BENJAMIN, Walter. The work of art in the age of mechanical reproduction. In: DURHAM, Meenakshi Gigi, KELLNER, Douglas M. (eds) Media and cultural studies: keywoks. Revised Edition. Malden, MA: Blackwell Publ., 2006. p. 18-40. 
EISNER, Will. Comics \& sequential art. Tamarac, FL: Poorhouse Press, 2001.

GRAVETT, Paul. Graphic novels: everything you need to know. New York: HarperCollins, 2005.

GROENSTEEN, Thierry. Why are comics still in search of cultural legitimation? In: The System of Comics. The Crib Sheet, URL:http://thecribsheet-isabelinho.blogspot.com/2008/12/ thierry-grensteens-why-are-comics-still.html

MAGNUSSEN, Anne, CHRISTIANSEN, Hans-Christian (eds). Comics \& culture: analytical and theoretical approaches to comics. Copenhagen: Museum Tuscalanum Press, University of Copenhagen, 2000. p. 29-41.

HATFIELD, Charles. Alternative comics: an emerging literature. Jackson: University Press of Mississippi, 2005.

HORKHEIMER, Max, ADORNO, Theodor W. The culture industry: enlightenment as mass deception. In: DURHAM, Meenakshi Gigi, KELLNER, Douglas M. (eds). Media and cultural studies: keywoks. Revised Edition. Malden, MA: Blackwell Publ., 2006. p. 41-72.

KANNENBERG, Gene, Jr. 500 essential graphic novels: the ultimate guide. New York: Collins Design, 2008.

LOMBARD, Matthew, LENT, John, GREENWOOD, Linda, TUNÇ, Asli. A framework for studying comic art. International Journal of Comic Art, vol. 1, n. 1, p. 17-32, Spring/Summer 1999.

MARTINS, Raimundo. Porque e como falamos da cultura visual? Visualidades, Goiânia; UFG; v. 4, n. 1⁄2, p. 65-79, jan./jun. 2006.

MOYA, Álvaro de. Anos 50/50 anos : São Paulo 1951/2001: Edição comemorativa da Primeira Exposição Internacional de Histórias em Quadrinhos. São Paulo : Ed. Ópera Graphica, 2001.

NYBERG, Amy Kiste. Seal of approval: the history of the comics code. Jackson: University Press of Mississippi , 1998.

PASAMONIK, Didier. Critique de la bande dessine pure: chroniques narquoises: 2005-2007. Paris: Berg International, 2008.

SKINN, Dez. Comix: the underground revolution. New York: 
As histórias em quadrinhos no limiar de novos tempos: em busca de sua legitimação como produto artístico e intelectualmente valorizado

\section{Waldomiro Vergueiro}

é doutor e livre-docente em Ciências da Comunicação e Professor Titular do Departamento de Biblioteconomia e Documentação da Escola de Comunicações e Artes da Universidade de São Paulo (ECA-USP). Docente do Programa de Pós-Graduação em Ciências da Comunicação da ECA-USP, onde também coordena o Observatório de Histórias em Quadrinhos. Publicou os seguintes livros: Como usar as histórias em quadrinhos na sala de aula, O Tico-Tico: Centenário da primeira revista de histórias em quadrinhos no Brasil e Historieta Latinoamericana. v. 3: Brasil (na Argentina).

Endereço: Escola de Comunicações e Artes da Universidade de São Paulo, Av. Prof. Lúcio Martins Rodrigues, 443, Butantã, São Paulo, Rua Jorge Tibiriçá, 266, Vila Mariana, São Paulo, SP, 04126-000, Tel. 3091-4076, ramais 27 e 34; e-mail: wdcsverg@usp.br 